\title{
The Vietnam War in the New Century: The Evolution of Apocalypse Now Redux (2001) in Narrative Perspective
}

\author{
SHAO Bing-qing, LIU Xiao \\ National University of Defense Technology, Changsha, China
}

\begin{abstract}
Apocalypse Now is a 1979 American epic war film set during the Vietnam War, directed and produced by Francis Ford Coppola. It was originally adapted from the novella Heart of Darkness (1902), which was written in the colonial era. Apocalypse Now Redux (2001) is a refined version of the 1979 edition. In previous researches, most scholars only focused on either of the two adapted versions in terms of thematic discussion and narrative analysis, which have ignored the significance of the evolution of the film and the changing historical contexts. Accordingly, on the basis of narrative theory and cultural study, the thesis makes a narrative analysis of the evolution of Apocalypse Now Redux (2001). It indicates that through some newly-inserted narrative elements in Apocalypse Now Redux (2001), more attention is paid to minority groups, darkness in war and media quagmire, which is related to different historical and political contexts and endeavors to remind the American public of the harsh lesson of Vietnam War in the 20th century. However, efforts to restraint the war seem to be ineffective, which is fully exemplified by Iraq War in 2003.
\end{abstract}

Keywords: Apocalypse Now Redux (2001), Vietnam War, narrative theory, new century

\section{Introduction}

Vietnam War is definitely one of the most important wars in the 20th century, which caught great attention of and deep reflections among American writers. The works related to Vietnam War (including other cultural productions) inflicted not only huge impactions on veterans and their offsprings, but also those who advocated for the war. In various periods of American history, there are different focuses of Vietnam literature and art works.

In April of 1975, Vietnam War finally came to an end, after which the United States entered into a new era of "post-Vietnam War age". During the period, the content of almost all of Vietnam War movies is anti-war. Among them, Apocalypse Now is always considered as the first-rank Vietnam movie. Upon its release on 1979, though being controversial, it was honored with the Palme d'Or at Cannes, and nominated for the Academy Award for Best Picture and the Golden Globe Award for Best Motion Picture-Drama ${ }^{1}$, and it deemed "a legend even before its life time, and it had become almost the memorial to a period willed into hazy oblivion by the vast majority of Americans” (Adair, 1981, p. 143).

SHAO Bing-qing, bachelor of arts, Humanities and Social Sciences Department, National University of Defense Technology.

LIU Xiao, professor, Humanities and Social Sciences Department, National University of Defense Technology.

${ }^{1}$ Retrieved Oct. 25th, 2014 from http://en.wikipedia.org/wiki/Apocalypse_Now. 
After American's victory in the Gulf War in 1991, President George H. Bush famously announced at the conclusion of the conflict that "We've kicked the Vietnam Syndrome once and for all” (Mirra, 2011, p. 1). It became a predictive sign for the war movies of "good fight" to return to the forefront Hollywood, such as Pearl Harbor (2001), Black Hawk Down (2001) and so on. Nevertheless, Apocalypse Now Redux (2001) came forth countercurrent and stirred a huge wave among the mainstream pro-war movies.

So far, the researches on Apocalypse Now overseas have conducted different perspectives. Part of the researches explores the relations between the movie and its loose adaption—Conrad's Heart of Darkness (1902). Bogue (1981) suggests that the film could be viewed as an "imitation” of Conrad's novella (pp. 611-626). Part of the researches probes the ordinary antiwar theme. For example, Diane Jacobs mentions the "horror" theme in the movie. Other researches mostly make narrative analyses to interpret the characteristics of the movie. Whillock (1990) focuses on three narrative elements, the environment, the characters as well as the story motifs, and Lothe (2000) details the comparison and succession of narrative strategy between Heart of Darkness (1902) and Apocalypse Now (1979).

The studies have made great contribution to the understanding and evaluation of the film. Nevertheless, certain limitations still exist when it comes to the film's evolution by itself, since Apocalypse Now Redux (2001) is obviously not a simple replica of the original version. It is a re-arrangement of the full play and has restored another 49 minutes of scenes cut from the original film. Twenty years turned the political situation into a more tolerant environment for the director to rebuild the movie in a more objective and mature way, thus Coppola no longer wanted the film quite under the discipline of a conventional war film.

In the framework of narrative theory and culture study, this thesis will look into the newly-added scenes from three aspects of characterization, setting and speech in the specific context of culture, politics, and society of the post-Vietnam war era in the U.S., trying to approach the intention of the director and explore the significance of the film in today’s post-911 world.

\section{The Black and the Vulnerable}

According to Kenan (2005), character can be described in terms of a network of character-traits, which includes direct definition, indirect presentation, and reinforcement by analogy (p. 61).

In Apocalypse Now (1979), the Do Lung Bridge scene and the scenes of Clean and Chief's death all contribute to the depiction of black soldiers' situations and sacrifice in the Vietnam War. When it comes to the 2001 version, the inserted scene of Clean's funeral (see Table 1) further pays homage to the black soldiers through character-indicators that are more indirectly displayed in others' actions.

In French plantation, the family force and the remaining crew members hold a solemn funeral for Clean. The soldiers stand in lines and salute Clean with guns. A worn American flag covers Clean's body during the funeral, which implies the admission from the country for the contribution that Clean had made. Until the last minute of burial, Chief picks the flag back and puts Clean's tape on his corpse, since it is the only memorable thing that Clean has in his life time. It can be taken as a sign of honor and respect that the film intends to express. The respect is sent not only to Clean himself, but also to the whole group of black soldiers together, since all of them devote their lives during the Vietnam War for their country—The United States. 
Table 1

The Variation of Redux Version

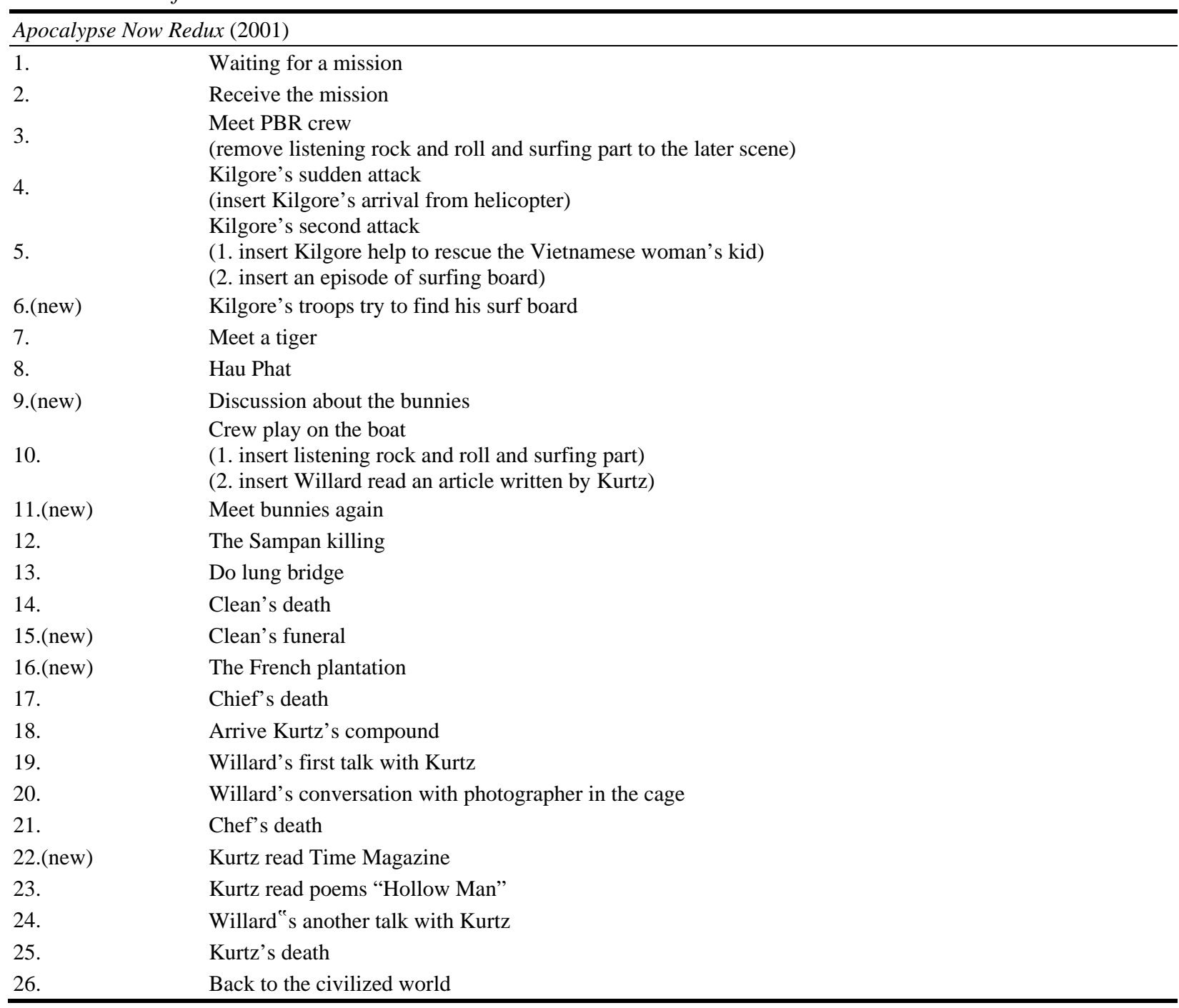

Chief, as one of the Black soldiers, cries with complicated emotions. On the emotional level, he is so sad with fellow's death; whereas on the symbolic level, as the funeral represents the recognition of the sacrifice of black soldiers, and Chief is deeply touched and soothed by this recognition. However, Coppola would rather not make his movie over stereotyped patriotic stories, as audience could still have a glimpse of his rebellion from one detail. During the mournful funeral, Willard is twice attracted by the shadow of a strange French woman. Though the satirical shot aims at foreshadowing the following plot, it still remains as a hypersensitive signal, which subconsciously implicates the disregard of white people for other ethnic groups.

From merely describing the tough condition of black soldiers to particularly inserting a solemn funeral of a black soldier, the movie has revealed the enhancement of social status of the blacks, which originated as a part of civil rights movement in 1950s and flourished in 1960s. Half a century has passed. The outcome of their democratic struggle is proved to be outstanding, which could be proved by the election of Obama as U.S. President. 
Besides the ethnic minority, Apocalypse Now Redux (2001) also shows humane care for the other vulnerable group-women. In the traditional viewpoint, the war asks women to leave. However, since the terror of Vietnam War is imposed on the whole American society, women unexceptionally become the victims of the war. Their images are built by speeches and soldiers' actions towards them.

In a stormy day, on their way upstream, PBR crew members come across the bunnies again who previously perform for the soldiers and are ironically scared away by them. Though this scene is depicted as foolish, amusing, and even erotic, people learn more about the miserable experiences of bunnies.

Women are objectified in Vietnam War. First of all, the bunnies appear as playmates on the battleground. Their job is to behave nastily and please the soldiers. Secondly, the bunnies are exchanged for only two barrels of fuels and exploited as objects. Thirdly, Lance and Chef both decorate the bunnies into appearances as they wish like toys. More ironically, when the playmate of the year thinks that she has found the "innocent boy", Clean slaps on the window and says he's the next.

Because of the tyranny imposed on them, the bunnies suffer a lot. Miss May is obviously developing psychedelic insanity, as she is indulged in her own world with her birds, caring nothing in the outside world. She talks to the Chef about her past and how she loves her work. At the same time, the playmate of the year keeps murmuring about her pathetic experience and expresses her solitary. She subconsciously depreciates herself and doesn't think she deserves an innocent relationship. She anxiously intends to show her talent, but all the men are more interested in her body.

Like the depiction of black soldiers, the emphasis on the part of women is the combined products with the feminist movement and the development of diversified society. The newly inserted factors reflect the humanistic feelings of Coppola towards minority groups, as well as the rising status of them.

\section{Dark Humanity and Political Reality}

Specific setting may function as crucial elements in the scenes. According to Mikhail Bakhtin ${ }^{2}$ (1975), the spatio-temporal setting constitutes the narrative and ideological center of the text, which he speaks of as chronotope. In the added scenes, there are certain setting devices that are quite interesting and arouse readers' thinking.

In the scene, Kilgore asks his soldier either to surf or to fight while shells are still exploding. They are bending over the boards looking frightened, in the setting of roaring flames, erupting spout and colorful smoke, which jointly turn the cruel war into a fevered party. The amusing surfing scene set in the flames of war generates sharp contrast, which manifests how Vietnam War releases the darkest side of human beings. Treating himself as an artist, Kilgore is no longer satisfied with killing and seeks for fun. His absurd action and extreme amusement on the battlefield fully exemplifies the distorted humanity of American soldiers and smashes the prevailing heroic images of soldiers in other war films.

Also, the scene of bunnies' first appearance is delicately designed. The bunnies are dancing with guns and pistols treating the killing machines as props of shows, and the soldiers are driven crazy by the seductive words and tempting actions. On the stage behind them there are huge cannonball models. In the dazzling lights, they look like giant male genitals that symbolize primitive sexual desires. What's more ironic, the whole camp is

\footnotetext{
2 Mikhail Mikhailovich Bakhtin (November 17, 1895-March 7, 1975) was a Russian philosopher, literary critic, semiotician and scholar who worked on literary theory, ethics, and the philosophy of language.
} 
wired in as a circus where the Vietnamese are enjoying shows from the outside. Some carry their children on the shoulders. Some carry the bowls eating. Others climb up the wire to get a better view. It is such a common scene in the countryside when theatrical troupe comes around. In between, the wire creates two worlds—normality and insanity, simplicity and extravagance, socialism and capitalism. Just like what Willard comments facing the mess the next morning, "the war was being run by a bunch of four-star clowns who were gonna end up giving the whole circus away" (Apocalypse Now Redux, 2001).

The French plantation is another interesting setting. The surrealist plantation is set in the middle of the journey up the Mekong River, which symbolizes the historical reflection of the First Indonesian War during a time journey tracing from the modern world back to the barbarous times. In the 1979 version, it was eliminated for the direct criticism on the U.S. side.

The conversation on the dinner table skillfully uncovers the motivation of the Vietnam War in political context. The film itself strategically gets rid of any unnecessary responsibility by borrowing opinions from French people as characters. If both the U.S. and Vietnam could not make a justified comment on the Vietnam War, then a criticism from a third perspective may seem to be more objective and convincing. The French argue that Americans are repeating the mistakes of them and have never learnt from history. They accuse Americans of triggering the war when they know nothing about Vietnamese and causing disastrous aftermaths in Vietnam, who finally trap themselves in South Asia. Further they extend the criticism to all the westerners, saying that it is right time for the white to evacuate from the Asia with the excuses of liberation and freedom.

The conversation reveals the essence of the First Indonesian War and Vietnam War, which is western colonialism of Asia. The wars are manipulated by the ambitious domestic politicians, and millions of innocent soldiers are sacrificed on the battlefield for meaningless and unjustified reasons in the conspiracies. If Americans still don't realize the fact, history will put on a old play. By setting this scene, Coppola intends to arouse the critical considerations and calmness in the victory of Gulf War, and calls for historical thinking in audiences.

\section{Media Revolution and Quagmire}

One of the impressive features of Apocalypse Now Redux (2001) is the direct criticism on American government. Coppola skillfully embeds some political indication related to media and U.S. government in Kurtz's speech when he is reading Time Magazine.

A notable event has to be mentioned when it comes to media during the Vietnam War. The New York Times is long regarded within the industry as a national "newspaper of record”3. It is well known that in 1971, the Pentagon Papers, which is a secret United States Department of Defense history of the United States' political and military involvement in the Vietnam War from 1945 to 1967, was leaked to The New York Times by a former researcher from Rand Corporation, Daniel Ellsberg ${ }^{4}$. The document enlarged the credibility gap between the U.S. Government and the public and intensified their conflicts. People no longer trusted the government and held

\footnotetext{
3 "The New York Times". Encyclopædia Britannica, cited in http://en.wikipedia.org/wiki/The_New_York_Times\#cite_note-EB-6.

${ }^{4}$ Daniel Ellsberg (born April 7, 1931) is an activist and former United States military analyst who, while employed by the RAND Corporation, precipitated a national political controversy in 1971 when he released the Pentagon Papers, a top-secret Pentagon study of U.S. government decision-making in relation to the Vietnam War, to The New York Times and other newspapers. He was awarded the Right Livelihood Award in 2006. He is also known for popularising part of decision theory, the Ellsberg paradox (postulated before by John Maynard Keynes in 1921).
} 
cynical attitudes towards efforts of Nixon administration to fight the on-going war. The U.S. government sued the newspaper for leaking state secrets but lost the lawsuit. This was the famous New York Times Co. v. United States 403 US 713. It was seen as a deterrence to the government and a victory of an absolute right to speech in American history. However, U.S. government learnt something from the event and started to control the media during the Gulf War. Since then, media is utilized as a weapon of propaganda.

The movie borrows the content of authoritative magazine so as to disclose the hypocritical face of American government and states the importance of media. When Willard is locked in a stone prison, Kurtz reads for him an article from Time Magazine, which is issued a year ago in 1967. It reveals that an inquiry into the state claims that the U.S. power is declining, while Lyndon Johnson fears that the public could not accept the optimistic conclusions and may never permit the report to be released. What's more, Time Magazine reports that a Rand corporation consultant tells President Nixon that "things felt much better and smelled much better" in Vietnam, which is obviously fake information.

From above, it is clear that Coppola brings up the iconic words of 1971 event, including Time Magazine, inquiries and Rand corporation, in an attempt to reveal government's manipulation of public opinion by releasing misleading information through mass media. In the movie, Coppola emphasizes the importance of media and arouses public attention in propaganda, which rings a bell for the public that media should serve to supervise the government for the benefit of the nation instead of being used as a puppet of to fool the public. It is a legitimate and fundamental right for media to scrutinize the government and uncover its corruption, scandals and all the dark trade in order to achieve democracy. It is a right that should be protected by the constitution and firmly supported by the public. However, in the 21st century, the censorship over media is intensified as propaganda is gradually recognized as a part of soft power. Since the authorities try to build the United States into a super media empire for its own interest, it is inevitable to control the voices both at home and abroad. Recently, media control again came into sight that the Pentagon sent 775 "embedded journalists” 5 to the Middle East during Iraq War. Apparently, Coppola has quite an insight towards the serious situation of media.

It seems that Americans always lack a true sense of history and tend to selectively erase the memories of historic error, which is more true among politicians, media, and movies. Thus, most of the Hollywood movies either romanticize, heroize, vulgarize or commercialize the war. Few of them has the gut to go against the trend and reopen old wounds of Vietnam War. Under such circumstance, Coppola stands out as a pioneer against Hollywood. He interprets history in his own way and challenges the official discourse in hope of reminding people of the harsh lesson on Vietnam land. Foreseeing the aftermath of the prevailing pro-war tendency, he is deeply worried and reproduced Apocalypse Now in 2001.

\section{Conclusion}

The uniqueness of the new version lies not only in the delicate scenes, but for its its evolutionary process. As a complicated social product, the self-evolution of the movie energetically gives a historical glimpse of the

\footnotetext{
${ }^{5}$ During Operation Iraqi Freedom, the Pentagon introduced a program “embedding” journalists in military units. These 775 reporters and photographers signed contracts with the military and promised not to report information that could compromise unit position, future weapons, and information they might find in disadvantage. The embedded journalists have been widely critized for inadequate reports of the war on Iraqi civilians and singular narratives of the U.S. troops.
} 
changing contexts of culture as well as the entire American society. Through the added plots in the redux version, people could obviously find an improved attitude towards ethnic groups and women, as well as deeper reflection on justification and the meaning of Vietnam War.

However, even though Apocalypse Now Redux (2001) is an anti-war movie, it lacks a certain all-around view of the war. It presents the unchanged value of ethnocentrism. Through the great contrast between highly advanced American military forces with enriched sensation and faceless Vietnamese soldiers with under-civilized wildness, Coppola lays more emphasis on the imbalance of two sides so as to depict the Vietnam War into an American tragedy. The world has been more familiar with the image of "the America in mournfulness", rather than the great loss of the Vietnamese part, which might be in fact much greater.

Despite the limitation on American perspective, the movie still provokes introspection of the public, a huge step for American films. Coppola predicts the dangerous tendency in the new century wishing to prevent the tragedy from happening again. Sadly, four months after the release of Apocalypse Now Redux (2001), 9/11 occurred. In just two years, Iraq War broke out, which is always regarded as another great failure of U.S. Army and compared to the Vietnam War. Now that U.S. Army has withdrawn from Iraq, yet it should never been forgotten that how the public was infuriated and instigated to trigger the war in anti-communism paranoia or anti-terrorism fury, as well as how many similarities there are between the Vietnam War and Iraq War. Pro-war ghost has never left America. Worse enough, it is secretly spreading on the continent in an extensively informationized era when propaganda could easily confuse and manipulate minds through newspaper, television, and especially Internet. Temporarily lurking under the anti-Iraq War protests, pro-war tendency is a dangerous trigger that could ignite war flames anytime.

\section{References}

Bogue, R. L. (1981). The heartless darkness of Apocalypse now. The Georgia Review, 35, 611-26.

Jacobs, D. (1981). Coppola films Conrad in Vietnam. In M. Klein, \& G. Parker (Eds.), The English Novel and the Movies. United States: Frederick Ungar Publishing Co., Inc..

Kenan, S. R. (2005). Contemporary fiction. Taylor \& Francis e-Library.

Lorrie, S. (1990). America rediscovered: Critical essays on literature and film of the Vietnam War. USA: Library of Congress Cataloging-in-Publication Data.

Lothe, J. (2000). Narrative in fiction and film. New York: Oxford University Press Inc..

Mirra, C. (2011). The mutation of the Vietnam syndrome: Underreported resistance during the 1991 Persian Gulf War. Peace \& Change, 36(2), 262-284.

Whillock, D. E. (1990). Narrative structure in Apocalypse now. In W. Owen, J. Gilman, \& S. Lorrie (Eds.), America Rediscovered: Critical Essays on Literature and film of the Vietnam War. USA: Library of Congress Cataloging-in-Publication Data. 